\title{
Overview of the molecular mechanisms contributing to the formation of cancer-associated adipocytes (Review)
}

\author{
YUNPENG TANG $^{1 *}$, WENKAI ZHANG $^{1 *}$, TIANQIANG SHENG ${ }^{1}, \mathrm{XI} \mathrm{HE}^{2}$ and XIANGYANG XIONG ${ }^{2}$ \\ ${ }^{1}$ Second Clinical Medical School; ${ }^{2}$ Department of Biochemistry and Molecular Biology, \\ School of Basic Medical Sciences, Nanchang University, Nanchang, Jiangxi 330006, P.R. China
}

Received May 10, 2021; Accepted August 24, 2021

DOI: $10.3892 / \mathrm{mmr} .2021 .12408$

\begin{abstract}
Adipocytes are the main stromal cells in the tumor microenvironment. In addition to serving as energy stores for triglycerides, adipocytes may function as an active endocrine organ. The crosstalk between adipocytes and cancer cells was shown to promote the migration, invasion and proliferation of cancer cells and to cause phenotypic and functional changes in adipocytes. Tumor-derived soluble factors, such as TNF- $\alpha$, plasminogen activator inhibitor 1, Wnt3a, IL-6, and exosomal microRNAs (miRNA/miRs), including miR-144, miR-126, miR-155, as well as other miRNAs, have been shown to act on adipocytes at the tumor invasion front, resulting in the formation of cancer-associated adipocytes (CAAs) with diminished reduced terminal differentiation markers and a dedifferentiated phenotype. In addition, the number and size of CAA lipid droplets have been found to be significantly reduced compared with those of mature adipocytes, whereas inflammatory cytokines and proteases are overexpressed. The aim of the present review was to summarize the latest findings on the biological changes of CAAs and the potential role of tumor-adipocyte crosstalk in the formation of CAAs, in the hope of providing novel perspectives for breast cancer treatment.
\end{abstract}

\section{Contents}

1. Introduction

2. Differentiation of adipocytes

3. Biological characteristics of CAAs

4. Possible mechanisms of tumor-mediated CAA development

Correspondence to: Dr Xiangyang Xiong, Department of Biochemistry and Molecular Biology, School of Basic Medical Sciences, Nanchang University, 461 Bayi Avenue, Nanchang, Jiangxi 330006, P.R. China

E-mail: xiangyangxiong@ncu.edu.cn

*Contributed equally

Key words: breast cancer, cancer-associated adipocytes, tumor-adipocyte crosstalk, tumor microenvironment, tumorigenesis
5. Role of CAAs in breast cancer progression

6. Perspectives

\section{Introduction}

The tumor microenvironment consists of several types of stromal cells, including adipocytes, fibroblasts, endothelial cells and macrophages (1). Imaging evaluation has revealed that adipose tissue occupies $56 \%$ of non-lactating breast tissue and $35 \%$ of lactating breast tissue $(2,3)$, suggesting that adipocytes account for a major part of the breast tumor microenvironment. Adipocytes, preadipocytes, fibroblasts, immune cells, endothelial cells and extracellular matrix (ECM) are the main components of adipose tissue, which is divided into white, brown and beige adipose tissue $(4,5)$. White adipocytes are the most abundant fat cells in the human body, and previous findings have associated white adipose tissue (WAT) with an increased risk of breast cancer (6). In addition to serving as an energy reservoir for triglycerides, adipose tissue is an active endocrine organ that secretes hormones, adipokines, cytokines, chemokines and proinflammatory molecules (7). Existing studies have confirmed the hypothesis that adipocytes and cancer cells interact dynamically (8-10), as opposed to adipocytes being previously considered as static cells neighboring cancer cells. Previous studies have mostly focused on the role of adipocytes in the proliferation and migration of cancer cells, with little attention to the changes in adipocytes (11). A particular class of adipocytes, referred to as cancer-associated adipocytes (CAAs), have been identified in the matrix surrounding invasive breast cancer (12). Therefore, in addition to summarizing the biological characteristics of CAAs, the aim of the present review was to further focus on the underlying mechanisms that contribute to CAA development, in the hope of providing new perspectives for breast cancer treatment.

\section{Differentiation of adipocytes}

Adipocytes originate from mesenchymal stem cells (MSCs) (13). MSCs are found in the bone marrow, adipose tissue and dental pulp (14), and they are multipotent cells that can differentiate into adipocytes, chondrocytes, muscle cells and osteocytes (15). Studies have found that MSCs highly 
express CD44, CD73, CD90 and CD105, which can be used as MSC markers (16). When the human body is in a state of excessive energy consumption and elevated glucose demands over a prolonged period of time, MSCs can be induced in a multi-step commitment process by one or more undetermined signals, limiting the differentiation of progenitor cells into the adipocyte lineage (17). As a key mediator for stem cells to commit and generate preadipocytes, the bone morphogenetic protein and Wnt families can upregulate the expression of cytoskeleton-related proteins, such as lysine oxidase, translation-controlled tumor protein $1, \alpha \mathrm{B}$ crystallin and lymphoid enhancer factor1/T-cell factor (Tcf) to promote preadipocyte commitment (18-20). When committed preadipocytes are exposed to a differentiation inducer comprising a mixture of dexamethasone, isobutylmethylxanthine and insulin, the CCAAT/enhancer binding protein $\beta(\mathrm{C} / \mathrm{EBP} \beta)$ acquires DNA-binding activity consistent with the re-entry of preadipocytes into the cell cycle at the G1/S boundary, and undergoes approximately two rounds of division, known as mitotic clonal expansion (21). During this process, $\mathrm{C} / \mathrm{EBP} \beta$ binds to $\mathrm{C} / \mathrm{EBP}$ regulatory elements in the proximal promoters of $\mathrm{C} / \mathrm{EBP} \alpha$ and peroxisome proliferator-activated receptor $\gamma(\operatorname{PPAR} \gamma)$ genes, transactivating C/EBP $\alpha$ and PPAR $\gamma$ (21), which are two key adipogenic transcription factors involved in preadipocyte differentiation (22). Both C/EBP $\alpha$ and PPAR $\gamma$ can supervise the whole process of terminal differentiation and establish a mature adipocyte phenotype $(23,24)$. The expression of PPAR $\gamma$ and $\mathrm{C} / \mathrm{EBP} \alpha$ promotes transactivations through their respective $\mathrm{C} / \mathrm{EBP}$ regulatory elements, inducing the expression of numerous adipocyte-specific genes, such as fatty acid-binding protein 4 (FABP4) (25), insulin-responsive glucose transporter 4 (GLUT4) $(25,26)$, perilipin (PLIN) and insulin receptor (21), and the expression of enzymes, such as lipoprotein lipase (LPL) and fatty acid synthase (FAS). Adipocytes, on the other hand, secrete adipokines, such as leptin $(27,28)$, adiponectin (APN) (29), resistin (30), and others. The expression of preadipocyte factor-1, one of the key negative regulators of adipogenesis, is downregulated $(31,32)$. Consequently, due to commitment and differentiation induction, MSCs lose their fibroblast-like characteristics, accumulate a large number of cytoplasmic triglycerides, and obtain the appearance and metabolic characteristics of mature adipocytes.

\section{Biological characteristics of CAAs}

Cancer-adjacent adipocytes can be transformed into CAAs after communicating with cancer cells, adopting a dedifferentiation phenotype and secreting a significant number of proinflammatory cytokines, thereby promoting malignant tumor progression $(12,33)$. The main characteristics of CAAs are described below:

Loss of terminal differentiation markers. The expression of PPAR $\gamma$ and C/EBP $\alpha$ is significantly inhibited, which results in a substantial reduction in the mRNA levels of adipocyte-specific genes, including FABP4 and hormone-sensitive lipase (HSL), resulting in dedifferentiation of mature adipocytes $(12,34)$. The reduction of lipid content and cell size triggers the release of metabolites by CAAs, including free fatty acids and ketone bodies, to facilitate tumor progression (34-36). This effect was shown to be significantly enhanced in a cell culture model of obesity (36). Furthermore, the expression and activity of LPL and FAS in adipose tissue adjacent to the tumor invasion front were found to be significantly decreased, and the adipogenesis and fat storage capacity in patients with colorectal cancer were impaired (37). These changes may cause lipolysis in adipocytes, which then assume a fibroblast-like morphology.

Changes in the expression of adipokines and proinflammatory cytokines. In CAAs, the expression of pro-tumorigenic adipokines, such as leptin and resistin, is increased, while the expression of the anti-tumorigenic adipokine, APN, is markedly decreased (12). CAAs also exhibit increased expression and secretion of proinflammatory cytokines, such as IL-6, IL-1 $\beta$ and TNF- $\alpha(12,38)$, and chemokines, such as C-C motif chemokine ligand (CCL)5, CCL2 and IL-8 (also known as CXCL8), causing an increase in cancer invasive and metastatic ability (39-41). Our transcriptome sequencing data revealed that CAAs exhibited a higher expression of granulocyte colony-stimulating factor, which can promote the malignant progression of breast cancer via the STAT3 pathway (Fig. 1) (42).

ECM remodeling. Overexpression of ECM-related molecules, such as MMP11 (43), plasminogen activator inhibitor 1 (PAI-1) (12), MMP1 (44), fibroblast-activating protein, dipeptidyl peptidase 4, procollagen-lysine and 2-oxoglutarate 5-dioxygenase 2 (PLOD2), promote the transformation of adipocytes into cells with a fibroblast-like phenotype, which eventually develop into adipocyte-derived fibroblasts (ADFs). ADFs are characterized by increased secretion of fibronectin and type I collagen, as well as upregulated expression of the cancer-associated fibroblast (CAF) marker fibroblast-specific protein I, but not $\alpha$-smooth muscle actin ( $\alpha$-SMA). ADFs exhibit enhanced ability of migration and invasion, and can reach the tumor center, significantly promoting tumor invasion (45-47).

WAT browning. Master et al (48) demonstrated that the breast contains brown adipose tissue (BAT), which plays a potential role in adaptive thermogenesis. Furthermore, Wang et al (49) found that the expression levels of BAT marker genes, such as uncoupling protein (UCP1), protein 16 containing PR domain (PRDM16) and cell death-inducing DFFA-like effector A, were upregulated in CAAs from patients with breast cancer, and the browning activity of adipocytes adjacent to the breast cancer tissues was higher compared with those adjacent to benign breast lesions. Previous studies indicated that tumor-derived IL-6 induced adipose tissue browning via the STAT3 pathway, and that microRNA (miRNA/miR)-155 can promote the browning of adipocytes by downregulating PPAR $\gamma$ expression $(50,51)$. Compared to WAT, BAT has a stronger catabolic ability and can provide high-energy mitochondrial fuel in the form of ketone bodies to support the growth of tumors such as skin and colon cancer (35).

\section{Possible mechanisms of tumor-mediated CAA development}

Tumors secrete numerous types of factors that induce the transformation of adipocytes into CAAs. The factors secreted 


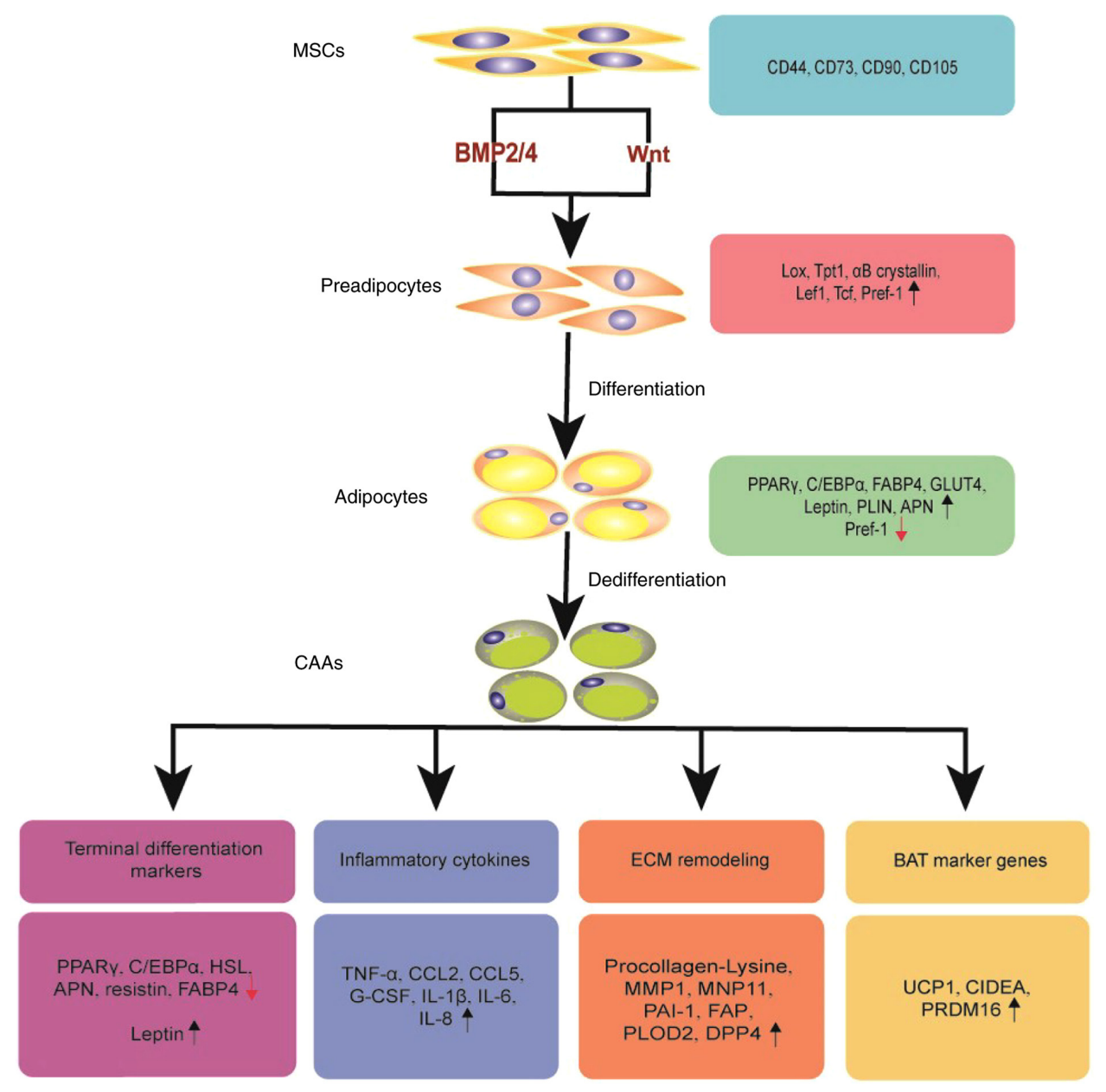

Figure 1. Differentiation of MSCs into adipocytes and biological characteristics of CAAs. MSCs can differentiate into preadipocytes through the BMP2/4 and Wnt pathways, and then preadipocytes can be further induced to transform into adipocytes after being treated with a differentiation induction mixture, resulting in an increased adipocyte-specific gene expression and lipid accumulation. Adipocytes adjacent to cancer can dedifferentiate into CAAs. The main characteristics of CAAs include decreased terminal differentiation markers, secretion of multiple inflammatory factors, ECM remodeling and expression of browning genes. MSCs mesenchymal stem cells; CAAs, cancer-associated adipocytes; BMP, bone morphogenetic protein; Lox, lysine oxidase; Tpt1, translation-controlled tumor protein 1; Lef1, lymphoid enhancer factor 1; Tcf, T-cell factor; Pref-1, preadipocyte factor 1; PPAR $\gamma$, peroxisome proliferator-activated receptor $\gamma$; C/EBP, CCAAT/enhancer binding protein; FABP4, fatty acid-binding protein 4; GLUT4, glucose transporter 4; PLIN, perilipin; APN, adiponectin; HSL, hormone-sensitive lipase; CCL, C-C motif chemokine ligand; G-CSF, granulocyte colony-stimulating factor; PAI-1, plasminogen activator inhibitor 1; ECM, extracellular matrix; FAP, fibroblast-activating protein; PLOD2, procollagen-lysine and 2-oxoglutarate 5-dioxygenase 2; DPP4, dipeptidyl peptidase 4; BAT, brown adipose tissue; UCP1, uncoupling protein; PRDM16, protein 16 containing PR domain.

by CAAs, such as IL-8 and autotaxin (ATX), can also maintain their activated state and provide favorable conditions for tumor growth and metastasis.

TNF- $\alpha$. Tumor-derived TNF- $\alpha$ can promote the formation of CAAs by selectively downregulating the expression of PPAR $\gamma$ and $\mathrm{C} / \mathrm{EBP} \alpha$ (52). Stephens and Pekala (53) demonstrated that culturing differentiated 3T3-L1 adipocytes with TNF- $\alpha$ significantly inhibited $\mathrm{C} / \mathrm{EBP} \alpha$, GLUT4 and FABP4 gene expression in adipocytes. Interestingly, TNF- $\alpha$ was found to significantly reduce the stability of these mRNAs, which further prevented the accumulation of GLUT4 and $\mathrm{C} / \mathrm{EBP} \alpha$ proteins. The marked reduction in $\mathrm{C} / \mathrm{EBP} \alpha$ protein levels may lead to the enhancement of transcriptional inhibition of $\mathrm{C} / \mathrm{EBP} \alpha$, GLUT4 and FABP4 genes by TNF- $\alpha$. In addition, treatment with TNF- $\alpha$ activates the NF- $\kappa \mathrm{B}$ pathway in adipocytes, which further enhances the binding of p65 to the miR-130 promoter. The upregulation of miR-130 eventually leads to a decrease in PPAR $\gamma$ mRNA to preadipocyte levels (54). Furthermore, by decreasing the terminal differentiation markers, TNF- $\alpha$ increases lipolysis in WAT. Treatment with TNF- $\alpha$ was shown to increase the levels of inducible nitric oxide synthase (iNOS) and nitric oxide (NO) in multiple tissues, including adipose tissue, activating cAMP/cGMP and stimulating HSL phosphorylation, resulting in a significant increase in lipolysis (55). PLIN is a key regulator of HSL that is located on the surface of intracellular triglyceride lipid droplets. Exposing adipocytes to a TNF- $\alpha$-rich tumor microenvironment can downregulate PLIN expression to mediate lipolysis via the ERK1/2 and JNK pathways (56). In addition, in TNF- $\alpha$-treated adipocytes, the expression of the cyclic nucleotide phosphodiesterase $3 \mathrm{~B}$ (PDE3B), a key hydrolase of insulin-activated cAMP, was shown to decrease by $50 \%$, resulting in an increase in intracellular cAMP content and enhanced lipolysis (57-59). The loss of terminal differentiation markers and the synergistic effect of enhanced lipolysis promote the transition of mature adipocytes from the adipocyte phenotype to the spindled fibroblast-like phenotype. 
$I L-6$. The crosstalk between inflammatory signals, such as IL-6, from tumor tissue, adipose tissue and other organs, can cause energy imbalance and promote fat mobilization and catabolism $(60,61)$. Petersen et al $(62)$ showed that IL-6 can directly act on adipose tissue to enhance lipolysis in vivo and in vitro. Tumor-derived IL-6 binds to glycoprotein 130 (gp130) to enhance the adipose triglyceride lipase (ATGL)-stimulated lipolysis cascade via the AMP-activated protein kinase (AMPK) pathway, resulting in free fatty acids for breast cancer cells $(50,63)$, which then induce the migration and invasion of breast cancer cells (64). Tsoli et al (50) also discovered that IL-6 can enhance insulin signaling interference by upregulating the expression of suppressor of cytokine signaling 3, which phosphorylates and activates the STAT3 pathway, reducing glucose uptake and the synthesis other lipid substrates by WAT, inhibiting lipid synthesis and promoting the atrophy of WAT (65). Interestingly, WAT browning is known to involve paracrine and neuroendocrine signaling, which can be used by the transcription factor PRDM16 to induce the expression of genes related to lipid utilization and thermogenesis, such as UCP1 (66). The STAT3 signaling pathway can activate the PRDM16 gene, promoting the browning of WAT $(50,66)$. IL-6 also enhances sympathetic activity, causing further stress-mediated release of IL-6 from BAT (67). Adipocytes co-cultured with tumor cells can increase the level of IL- 6 by upregulating mmu-miR-5112 and downregulating the expression of cytoplasmic polyadenylation element-binding protein 1, a negative regulator of IL-6 (68). In addition, tumor-secreted leukemia inhibitory factor, a member of the IL- 6 cytokine family, can activate the Janus kinase (JAK)/STAT pathway through gp130 and induce ATGL activation to enhance lipolysis (69).

$I L-8$. CAAs expressing high levels of inflammatory cytokines, adipokines and proteases are considered to be adipocytes at an active state, as mentioned above. Compared to adipocytes at a distance from the tumor invasion front, CAAs are characterized by a high proliferation rate and strong invasive and migratory abilities. Al-Khalaf et al (70) isolated CAAs and their adjacent tumor-counterpart adipocytes (TCAs) from 10 patients with invasive breast cancer and found that IL-8 plays a key role in maintaining the activation of CAAs. It was also previously reported that all CAAs secrete high levels of IL-8, which helps to induce the migration of ovarian cancer cells to adipocyte-rich areas (34). In addition, the basic and active forms of the AKT and STAT3 proteins, which are downstream effectors of IL-8 signaling, are higher in CAAs compared with those in TCAs. The ectopic expression of IL-8 in TCAs may cause their self-activation. According to Hendrayani et al (71), the activation state of CAFs is maintained via an IL-6/NF- $\kappa$ B/Lin28b positive feedback loop. Consistently, treatment of CAAs with anti-IL- 8 antibody decreases the mRNA levels of IL-6, RelA and Lin28b, and inhibits the activated state of CAAs. These results suggest that IL-8 may maintain the activity of CAAs by activating the IL-6/NF- $\kappa$ B/Lin28b positive feedback loop (70).

Wnt $3 a$ and Wnt5a. Breast cancer cells secrete Wnt3a, which activates the Wnt/ $\beta$-catenin pathway and induces the dedifferentiation of mouse and human adipocytes, acquiring an
ADF-like phenotype (72). In adipocytes co-cultured with breast cancer cells, Wan3a upregulates the expression of Wnt target genes, such as dishevelled-1, Wnt10b, endothelin-1 and MMP7, via a $\beta$-catenin-dependent pathway $(45,73)$. Wnt10b is known to block adipocyte differentiation by suppressing PPAR $\gamma$ and C/EBP $\alpha$ expression. Treatment with ICG-001, a unique small molecule that selectively inhibits Tcf $/ \beta$-catenin transcription, significantly inhibits the increase of Wnt10b expression, partially restores the lipid accumulation and reverses the ADF phenotype (45). Zoico et al (70) and Kang et al (71) demonstrated that pancreatic cancer can induce adipocyte dedifferentiation through a Wnt5a-dependent signaling pathway. The JAK/STAT3 pathway is activated by adipocyte-derived inflammatory factors when pancreatic cancer cells are co-cultured with adipocytes, leading to an increase in Wnt5a expression (74). The inhibition of adipogenesis by Wnt5a expressed by immune cells, such as macrophages, is well known (75). However, the opposite results have also been observed in other types of cancer $(76,77)$, which may be explained by the different expression levels of Wnt5a isotypes. Wnt5a-long (L) can inhibit tumors, whereas Wnt5a-short (S) can promote tumors (77). The expression of Wnt5a-L was found to be more pronounced in adipocytes co-cultured with pancreatic cancer cells (Fig. 2) (74).

MMP11. MMP11, which is also known as stromelysin-3, is a connective tissue-derived factor that is usually associated with tumor invasion and poor prognosis (78). The expression of MMP11 in adipocytes can be significantly increased during the crosstalk between cancer cells and adipocytes (43). Andarawewa et al (43) found that MMP11 was expressed in adipocytes located adjacent to the invasive breast cancer, but not in distally located adipocytes. Northern blotting analysis demonstrated that the expression levels of PPAR $\gamma$ and FABP4 in MMP11-deficient mice were higher compared with those in wild-type mice with stronger adipocyte differentiation potential, suggesting that MMP11 is a negative physiological regulator of adipogenesis. In addition to reducing the differentiation of preadipocytes, MMP11 induces the dedifferentiation of mature adipocytes. Treatment with MMP11 decreases the number and size of lipid droplets in adipocytes, reduces the number of adipocytes exhibiting a round phenotype, and increases the number of fibroblast-like cells (43). Compared with FABP4, the expression of PPAR $\gamma$ in MMP11-deficient tissues was found to be unregulated, suggesting that MMP11 may impede adipogenesis by downregulating the expression of PPAR $\gamma$ (43). According to previous studies, MMP11 is expressed in fibroblasts surrounding invasive cancer cells $(79,80)$. Interestingly, these fibroblasts do not express $\alpha$-SMA. Therefore, MMP11-expressing fibroblasts around the tumor may partially transdifferentiate from adipocytes or preadipocytes. Motrescu et al (81) further demonstrated that MMP11 can specifically degrade the natural $\alpha 3$ chain of collagen VI and change the ECM of tumors, unlike resting adipocytes, which are surrounded by thin strands of collagen VI. These results suggest that cancer cells can induce MMP11 expression in adipocytes by secreting soluble substances or through direct contact, resulting in an increased CAA phenotype and a high proportion of tumor matrix fibroblasts (43). 


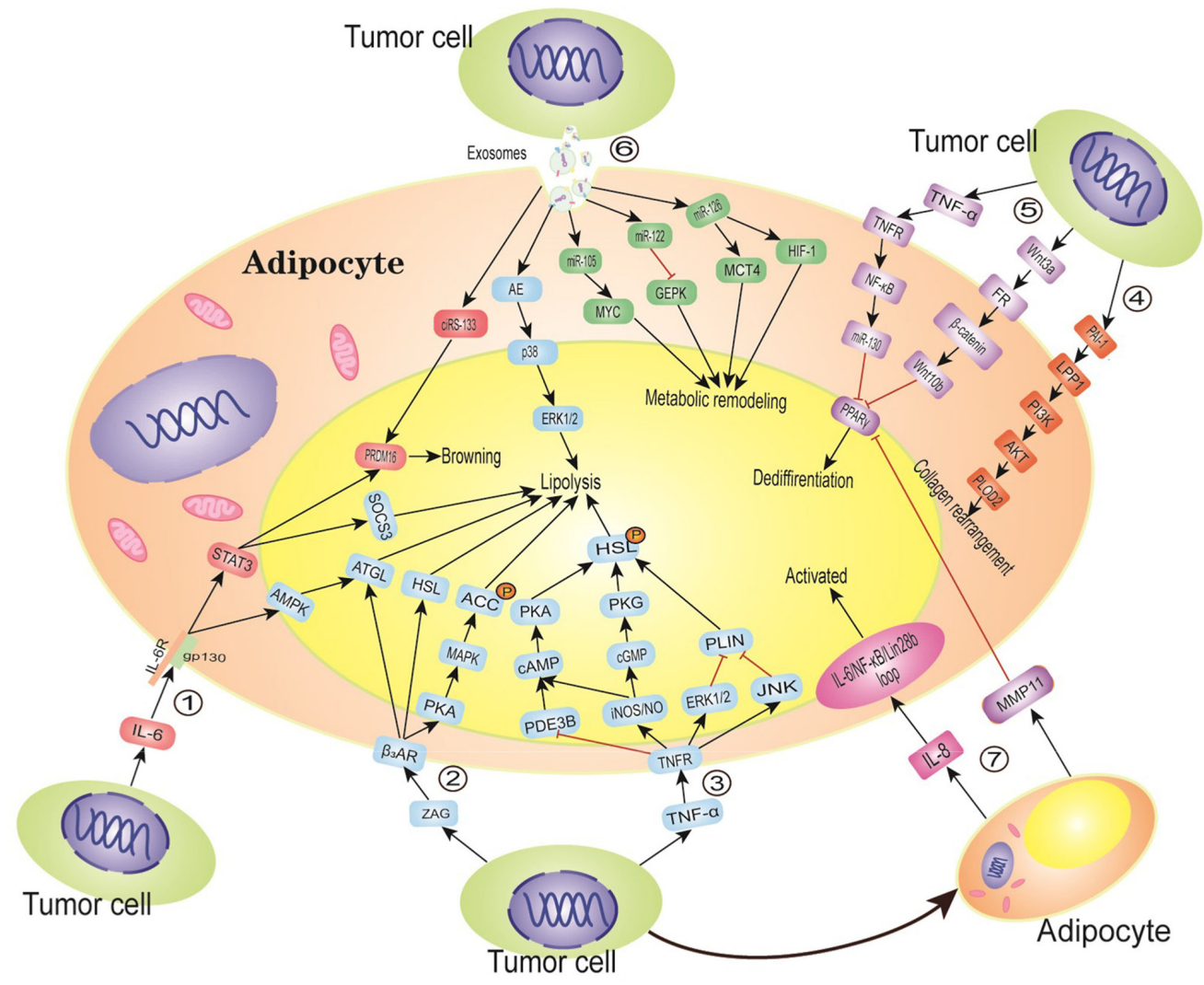

Figure 2. Possible mechanism of tumor-mediated CAA formation. (1) In tumor cells, overexpressed IL-6 binds to adipocyte gp130 and enhances ATGL-mediated lipolysis via the AMPK pathway. Furthermore, activation of the STAT3 pathway increases SOCS3 expression, which promotes lipid decomposition while inhibiting lipid synthesis. The activation of the STAT3 pathway also increases the expression of PRDM16. (2) Tumor-derived ZAG binds to $\beta 3 A R$ to stimulate lipid decomposition by upregulating the levels of ATGL, HSL and phosphorylated ACC through the MAPK signaling pathway. (3) TNF- $\alpha$ induces iNOS/NO in adipose tissue, leading to an increased cAMP and cGMP levels. In addition, the ERK1/2 and JNK-mediated reduction of PDE3B and PLIN expression enhances the phosphorylation of HSL and decreases the number and size of lipid droplets. (4) PAI-1 activates the LRP-1-dependent PI3K/AKT signaling pathway and promotes the activation of PLOD2 in CAAs, leading to collagen remodeling and extracellular matrix recombination. (5) Wnt3a enhances downstream Wnt10b transcription through ectopic accumulation of $\beta$-catenin in the nucleus. TNF- $\alpha$ can also upregulate miRNA-130 expression via the NF-kB pathway, which acts synergistically with Wnt10b to inhibit the transcription of PPAR $\gamma$ and dedifferentiate adipocytes. (6) Tumor-derived miR-105 activates MYC signaling and induces metabolic changes in adipocytes. miR-122 reduces the inhibitory effect of GEPK on glucose uptake. miR-126 upregulates HIF-1 and MCT4 protein expression and induces metabolic remodeling of adipocytes. The p38-ERK1/2-mediated lipolysis is induced by AE. ciRS-133 activates PRDM16 to promote adipocyte browning. (7) Adipocyte-derived IL-8 maintains the activation of CAAs, and adipocyte-derived MMP11 dedifferentiates adipocytes via blocking PPAR $\gamma$. CAAs, cancer-associated adipocytes; gp130, glycoprotein 130; ZAG, zinc- $\alpha 2$-glycoprotein; $\beta 3$ AR, $\beta 3$ adrenoceptor; ACC, acetyl-CoA carboxylase; ATGL, adipose triglyceride lipase; AMPK, AMP-activated protein kinase; iNOS, inducible nitric oxide synthase; NO, nitric oxide; PDE3B, phosphodiesterase 3B; PLIN, perilipin; HSL, hormone-sensitive lipase; PAI-1, plasminogen activator inhibitor 1; LRP-1, LDL receptor-related protein 1; PLOD2, procollagen-lysine and 2-oxoglutarate 5-dioxygenase 2; PRDM16, protein 16 containing PR domain; SOCS3, suppressor of cytokine signaling 3; MCT4, monocarboxylate transporter 4; GEPK, glycolytic enzyme pyruvate kinase; PPAR $\gamma$, peroxisome proliferator-activated receptor $\gamma$; HIF, hypoxia-inducible factor; AE, adrenomedullin; ciRS-133, circRNA sponge for miR-133; miR, microRNA.

PAI-1. PAI-1 is a mesenchymal marker that has been linked to the progression of a variety of cancers. Overexpression of PAI-1 has been associated wit a poor prognosis of breast cancer, particularly triple-negative breast cancer. The expression of PAI-1 is upregulated in both adipocytes and breast cancer cells after co-culture, but breast cancer cells secrete five-fold higher PAI-1 amounts than adipose cells (47). It has been revealed that PAI-1 mediates signal transduction by binding to cell membrane receptors, such as LDL receptor-related protein 1 (LRP-1) (82). In addition, available data indicate that LRP-1 is highly expressed in adipocytes and CAAs, and a high concentration of PAI-1 $(200 \mathrm{ng} / \mathrm{ml})$ can upregulate the expression of LRP-1 in adipocytes (47). The LRP-1-dependent simulation of the PI3K/AKT signaling pathway promotes the activation of PLOD2 (a lysine hydroxylase gene) in CAAs, whereas knocking down PAI-1 in MDA-MB-231 cells blocks the upregulation of PLOD2 expression in CAAs, suggesting that
PAI-1 is an important regulatory factor (47). The activation of PLOD2 can stimulate the rearrangement of adipocyte-derived collagen into a linear structure and promote the metastasis of cancer cells along the recombinant linear collagen fibers (47).

ATX/lysophosphatidylcholine (LPC) signaling. ATX is a secreted enzyme that catalyzes the hydrolysis of LPC, the most abundant phospholipid in the plasma, to produce vast amounts of lysophosphatidic acid (LPA) (83). LPA signaling is mediated by at least six G protein-coupled receptors (LPA1-6) $(84,85)$, and it promotes cell survival, proliferation and migration, while also controlling a variety of physiological and pathological processes (86-88). Popnikolov et al (89) demonstrated that ATX is mainly present in stromal cells. Adipose tissue is the main source of ATX in the circulation. Therefore, obesity and a high-fat diet may increase the production of ATX in adipocytes (90). In comparison to the surrounding breast fat 
pad, a syngeneic breast cancer model revealed that 4T1 cells express negligible amounts of ATX (91). The activity of ATX can be inhibited by LPA or sphingosine 1-phosphate-related lipids. Moreover, Benesch et al (92) found that inflammatory cytokines, such as TNF- $\alpha$ and IL-1 $\beta$, produced by tumor cells can overcome the LPA-mediated inhibitory effect on ATX mRNA expression, suggesting that LPA and ATX may coexist in the tumor microenvironment. The levels of ATX mRNA and protein in the adipose tissue surrounding tumor tissues increase as breast cancer develops (91). The increased LPA signaling further promotes the production of inflammatory mediators in adipose tissue and tumors (93). Although the molecules implicated in the ATX pathway remain unclear, evidence indicates that tumor-derived cytokines can stimulate increased production of ATX in peripheral adipocytes, promoting tumor cell proliferation, migration, metastasis, and resistance to radiotherapy and chemotherapy in a paracrine manner $(84,86,90)$.

Zinc- $\alpha 2$-glycoprotein $(Z A G)$. ZAG is a $43-\mathrm{kDa}$ glycoprotein encoded by the AZGP-1 gene. Previous studies have shown that ZAG is produced by certain cancer cells and WAT, and is closely associated with the prognosis of several types of cancer $(94,95)$, including breast (96), colorectal (97), prostate (98), and other cancers. Further research has demonstrated that tumor-derived ZAG can regulate lipid metabolism and promote WAT browning (99). Overexpression of ZAG suppresses the expression of FAS, diacylglycerol acyltransferase and acetyl-CoA carboxylase (ACC) in mouse adipose tissue (100). On the contrary, ZAG binds to $\beta 3$ adrenoceptor $(\beta 3 \mathrm{AR})$ and upregulates the expression of ATGL, HSL and phosphorylated ACC via the protein kinase A (PKA)/p38 MAPK signaling pathway, promoting lipolysis and inhibiting adipogenesis (101). In 3T3-L1 preadipocytes, ZAG was shown to suppress the differentiation of preadipocytes by inhibiting the expression of PPAR $\gamma, \mathrm{C} / \mathrm{EBP} \alpha$ and the adipogenic enzyme FAS. According to Elattar et al (99), ZAG enhances the transcriptional translation of PRDM16 by stimulating the expression of PPAR $\gamma$ and early B cytokine 2. In addition, ZAG stimulates the expression of PPAR $\gamma$ and PPAR $\gamma$ coactivator $1 \alpha$, and promotes the recruitment of PPAR $\gamma$ into the UCP1 promoter, leading to increased UCP1 expression (99). Similarly, the ZAG/ 33 AR/PKA/p38 MAPK signaling pathway can enhance the expression of specific BAT markers (101).

Exosomes. Exosomes are small extracellular vesicles, with a diameter of 30-100 nm, derived from endosomal multivesicular bodies (MVBs). Exosomes are released in bursts when MVBs fuse with the cell membrane, and their contents, such as miRNAs, other non-coding RNAs, transcription factors, proteins and lipids, are transported to target cells to participate in cell-cell communication (102). The miRNA characteristics of exosomes are parallel to the miRNA expression profile of the tumor cells (103), suggesting that the miRNA expression pattern in body fluids, such as urine or saliva, can be analyzed to replace traditional needle biopsy for early diagnosis of breast cancer.

Breast cancer cell-derived exosomes transport miRNAs, such as miR-144, miR-126 and miR-155, to resident cells in the breast cancer microenvironment, inducing the formation of CAAs (35). Previous studies have shown that cancer cell-derived miR-144 can target the MAP3K8 gene and reduce the phosphorylation level of ERK1/2 (35), resulting in the inhibition of PPAR $\gamma$ S273 phosphorylation in adipocytes, increased expression of UCP1 and browning of WAT $(35,104)$. Tumor-derived miR-126 can downregulate the expression of GLUT4 in adipocytes by directly targeting the insulin receptor substrate 1 gene. Furthermore, miR-126 can activate AMPK and increase the protein levels of hypoxia-inducible factor- $1 \alpha$ and monocarboxylate transporter 4 , resulting in metabolic remodeling of adipocytes, which is characterized by decreased glucose uptake and increased glycolysis and secretion of metabolites such as lactic acid and pyruvate $(35,105)$. Breast cancer cell-derived miR-155 can promote the beiging/browning and metabolic remodeling of adipocytes by downregulating the expression of PPAR $\gamma$ (51). In addition, higher levels of circulating miR-122 have been associated with breast cancer metastasis. Cancer cell-secreted miR-122 inhibits glucose uptake of premetastatic niche cells by reducing the activity of the glycolytic enzyme pyruvate kinase, which promotes the progression of the disease (106). Similarly, the expression of breast cancer-secreted miR-105 activates MYC signaling in CAFs and CAAs, which allows them to fuel neighboring cancer cells by enhancing glucose and glutamine metabolism under adequate nutrient conditions (107). In addition, the liver cancer secretes exosomes, which can activate the $\mathrm{NF}-\kappa \mathrm{B}$ signaling pathway in adipocytes to promote tumor growth and angiogenesis, and recruit additional macrophages (108). Pancreatic cancer cells can transfer exosomal AE and induce lipolysis of CAAs by activating the p38 and ERK1/2 pathways $(109,110)$. Advanced Lewis lung cancer can also secrete exosomal IL-6, leading to skeletal muscle atrophy and adipose tissue browning via activation of the IL-6/STAT3 pathway (111). Gastric cancer cells can transfer exosomal ciRS-133 (circRNA sponge for miR-133) to preadipocytes and induce brown adipocyte differentiation by activating PRDM16 and inhibiting the expression of miR-133 (109,112). Furthermore, adipocyte-derived exosomal miR-21 can be transferred to tumor cells to promote their proliferation, invasion and migration, drug resistance and angiogenesis (113-115). Lazar et al (116) found that adipocyte-derived exosomes can stimulate melanoma invasion and metastasis by fatty acid oxidation. Adipocyte-derived exosomal MMP3 can also promote lung cancer metastasis by increasing the activity of MMP9, which adversely affects the prognosis of patients with lung cancer (Fig. 2) (117).

Taken together, the aforementioned tumor-derived cytokines or miRNAs target CAAs via a paracrine mechanism, and one or more biological changes occur during the transition from mature adipocytes to CAAs through the activation of the NF- $\kappa \mathrm{B}, \mathrm{ERK}$, $\beta$-catenin and other signaling pathways. Initially, tumor-derived cytokines or miRNAs suppress the expression of the adipocyte differentiation markers PPAR $\gamma$ and $\mathrm{C} / \mathrm{EBP} \alpha$, resulting in adipocyte lipolysis, increased expression of pro-inflammatory factors, ECM remodeling and browning, until the adipocytes are finally transformed into the unique CAAs.

\section{Role of CAAs in breast cancer progression}

CAAs play a key role in breast cancer progression. 'Activated' CAAs can promote the progression of breast cancer through regulating various aspects of tumor cell proliferation, 
epithelial-to-mesenchymal transition (EMT), invasion, metastasis and angiogenesis, by secreting chemokines (CCL2 and CCL5), inflammatory factors (IL-6, IL-1 $\beta$, TNF- $\alpha$ and VEGF), adipokines (leptin), exosomes (proteins involved in fatty acid oxidation and miR-21) and lipolysis products (fatty acids, lactic acid and ketone bodies) (11). In a similar manner, CAAs may contribute to the drug resistance of breast cancer. Studies have reported that fatty acids can be used as a structural unit for the synthesis of membrane phospholipids, which can change the lateral and transverse membrane dynamics of breast cancer cells to enhance their oxidative stress resistance and limit the drug intake (118). Furthermore, lipolysis products, such as fatty acids and lactate, profoundly affect the homeostasis and differentiation of various immune cells, promoting immune escape and tumor progression (119). Leptin can also activate $\mathrm{NF}-\kappa \mathrm{B}$ signal transduction to reduce the toxicity of chemotherapeutics in vitro (120). The elevated expression of IL-6 in CAAs can induce the cancer stem cell-positive phenotype by activating the STAT3/NF- $\kappa \mathrm{B}$ pathway, leading to chemotherapy resistance of HER2-positive breast cancer (121). In CAAs, the upregulation of the expression of matrix proteins, such as MMP11, MMP1 and collagen VI, may also be involved in cisplatin resistance (Fig. 3) (38).

\section{Perspectives}

CAAs can create a favorable microenvironment for tumor cell proliferation, invasion and migration, and communication between CAAs and tumor cells can further affect the prognosis of patients with cancer (11), suggesting that CAAs may represent a potential therapeutic target for breast cancer. However, the mechanisms underlying the formation of CAAs have yet to be completely elucidated, and several problems remain unresolved.

First, certain cytokines, such as TGF- $\beta$, strongly reduce PPAR $\gamma$ and $\mathrm{C} / \mathrm{EBP} \alpha$ expression and induce fibrosis in vivo (52). IL-11 and angiopoietin-like 4 are highly expressed in tumor cells (122), inhibit the differentiation of preadipocytes (123), or stimulate lipolysis by increasing adipocyte cAMP levels (124). In addition to the miRNAs mentioned above, Wu et al (35) also discovered that several miRNAs, including miR-22, miR-210 and miR-16, were found to be differentially expressed in MDA-MD-231 cell- and CAA-conditioned culture medium. However, whether those cytokines and novel tumor-derived miRNAs are involved in the formation of CAAs is unknown. HOX transcript antisense intergenic RNA (HOTAIR), a long non-coding (lnc)RNA released by exosomes, is highly expressed in a variety of tumor tissues $(125,126)$. Interestingly, cancer cells transfer exosomal HOTAIR to endothelial cells, resulting in increased expression of VEGFA and angiogenesis (127). However, the role of lncRNAs secreted by tumors in adipocytes requires further investigation in the future.

Second, ADFs in the tumor center no longer contain lipid droplets or express adipocyte markers, and CAFs have also been found to overexpress UCP1 and MMP11 (80,128), which makes ADFs indistinguishable from other CAFs, suggesting that CAAs may constitute a part of the CAF population.

Third, adipocytes can be attracted to tumors and some cancer cells preferentially migrate to sites rich in adipose tissue, indicating the potential application of adipocytes as cell-based

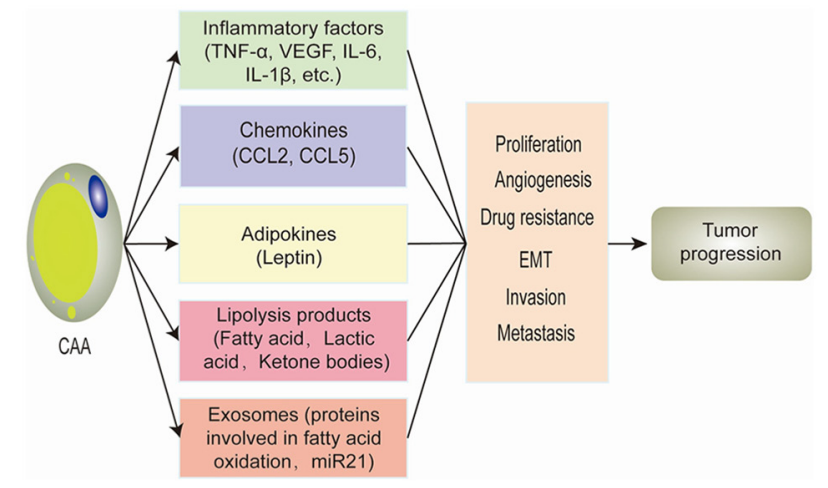

Figure 3. Role of CAAs in breast cancer progression. 'Activated' CAAs can secrete inflammatory factors (IL-6, IL-1 $\beta$ and TNF- $\alpha$ ), chemokines (CCL2 and CCL5), leptin, ketones and exosomes, which promote breast cancer cell proliferation, angiogenesis, drug resistance, EMT, invasion and metastasis CAAs, cancer-associated adipocytes; CCL, C-C motif chemokine ligand; EMT, epithelial-to-mesenchymal transition.

delivery platforms for drugs (or prodrugs), nanoparticles, or nucleic acids (129). However, in comparison, CAAs are more aggressive and in an active state, exhibiting increased expression of various inflammatory factors. CAAs can be cultured and isolated in vitro, making them more suitable for cell-based delivery platforms compared with normal mature adipocytes.

Finally, CAAs can be transformed from an 'accomplice' to a 'preventer' of tumors, which is of higher therapeutic value, by reversing their phenotype. However, due to the lack of uniform standards for CAA protein markers and related genes, it remains difficult to develop CAA-targeted treatments. Therefore, an in-depth understanding of the formation of CAAs in the breast cancer microenvironment should provide new insights into the treatment of breast cancer.

\section{Acknowledgements}

Not applicable.

\section{Funding}

The present study was funded by grants from the National Natural Science Foundation of China (grant no. 81760509) and the Natural Science Foundation of Jiangxi Province of China (grant no. 20181BAB205043).

\section{Availability of data and materials}

The datasets used during the present study are available from the corresponding author upon reasonable request.

\section{Authors' contributions}

XX, YT and WZ contributed to the concept and the design of this review. YT, TS and WZ wrote the manuscript. XX, YT, TS, WZ and XH helped draft the manuscript and drew the figures. XH and XX provided significant suggestions for the study. YT, TS and WZ searched the literature and collated important reference information. WZ and XX critically reviewed the manuscript. All the authors have read and 
approved the final manuscript and agree to be accountable for all aspects of the work in ensuring that questions related to the accuracy or integrity of any part of the work are appropriately investigated and resolved.

\section{Ethics approval and consent to participate}

Not applicable.

\section{Patient consent for publication}

Not applicable.

\section{Competing interests}

The authors declare that they have no competing interests.

\section{References}

1. Montel V, Mose ES and Tarin D: Tumor-stromal interactions reciprocally modulate gene expression patterns during carcinogenesis and metastasis. Int J Cancer 119: 251-263, 2006.

2. Vandeweyer E and Hertens D: Quantification of glands and fat in breast tissue: An experimental determination. Ann Anat 184: 181-184, 2002.

3. Ramsay DT, Kent JC, Hartmann RA and Hartmann PE: Anatomy of the lactating human breast redefined with ultrasound imaging. J Anat 206: 525-534, 2005.

4. Luo L and Liu M: Adipose tissue in control of metabolism. J Endocrinol 231: R77-R99, 2016.

5. Wang YX, Zhu N, Zhang CJ, Wang YK, Wu HT, Li Q, Du K, Liao DF and Qin L: Friend or foe: Multiple roles of adipose tissue in cancer formation and progression. J Cell Physiol 234 21436-21449, 2019.

6. Iyengar NM, Zhou XK, Mendieta H, Giri DD, El-Hely O, Winston L, Falcone DJ, Wang H, Meng L, Landa J, et al: Effects of adiposity and exercise on breast tissue and systemic metabo-inflammatory factors in women at high risk or diagnosed with breast cancer. Cancer Prev Res (Phila) 14: 541-550, 2021.

7. Nieman KM, Romero IL, Van Houten B and Lengyel E: Adipose tissue and adipocytes support tumorigenesis and metastasis. Biochim Biophys Acta 1831: 1533-1541, 2013.

8. Zhao C, Wu M, Zeng N, Xiong M, Hu W, Lv W, Yi Y, Zhang Q and $\mathrm{Wu}$ Y: Cancer-associated adipocytes: Emerging supporters in breast cancer. J Exp Clin Cancer Res 39: 156, 2020.

9. Uehara H, Kobayashi T, Matsumoto M, Watanabe S, Yoneda A and Bando Y: Adipose tissue: Critical contributor to the development of prostate cancer. J Med Invest 65: 9-17, 2018.

10. Picon-Ruiz M, Marchal JA and Slingerland JM: Obtaining human breast adipose cells for breast cancer cell co-culture studies. STAR Protoc 1: 100197, 2020.

11. Wu Q, Li B, Li Z, Li J, Sun S and Sun S: Cancer-associated adipocytes: Key players in breast cancer progression. J Hematol Oncol 12: 95, 2019.

12. Dirat B, Bochet L, Dabek M, Daviaud D, Dauvillier S, Majed B, Wang YY,Meulle A, Salles B,Le Gonidec S, et al: Cancer-associated adipocytes exhibit an activated phenotype and contribute to breast cancer invasion. Cancer Res 71: 2455-2465, 2011.

13. Kokabu S, Lowery JW and Jimi E: Cell fate and differentiation of bone marrow mesenchymal stem cells. Stem Cells Int 2016: 3753581, 2016.

14. Ridge SM, Sullivan FJ and Glynn SA: Mesenchymal stem cells: Key players in cancer progression. Mol Cancer 16: 31, 2017.

15. Han Y, Li X, Zhang Y, Han Y, Chang F and Ding J: Mesenchymal stem cells for regenerative medicine. Cells 8: 886, 2019.

16. Chen Q, Shou P, Zheng C, Jiang M, Cao G, Yang Q, Cao J, Xie N, Velletri T, Zhang X, et al: Fate decision of mesenchymal stem cells: Adipocytes or osteoblasts? Cell Death Differ 23: 1128-1139, 2016.

17. Shepherd PR, Gnudi L, Tozzo E, Yang H, Leach F and Kahn BB: Adipose cell hyperplasia and enhanced glucose disposal in transgenic mice overexpressing GLUT4 selectively in adipose tissue. J Biol Chem 268: 22243-22246, 1993.
18. Huang HY, Hu LL, Song TJ, Li X, He Q, Sun X, Li YM, Lu HJ, Yang PY and Tang QQ: Involvement of cytoskeleton-associated proteins in the commitment of $\mathrm{C} 3 \mathrm{H} 10 \mathrm{~T} 1 / 2$ pluripotent stem cells to adipocyte lineage induced by BMP2/4. Mol Cell Proteomics 10: M110.002691, 2011.

19. de Winter TJ and Nusse R: Running against the Wnt: How Wnt $/ \beta$-catenin suppresses adipogenesis. Front Cell Dev Biol 9: 627429, 2021.

20. Huang H, Song TJ, Li X, Hu L, He Q, Liu M, Lane MD and Tang QQ: BMP signaling pathway is required for commitment of C3H10T1/2 pluripotent stem cells to the adipocyte lineage. Proc Natl Acad Sci USA 106: 12670-12675, 2009.

21. Tang QQ and Lane MD: Adipogenesis: From stem cell to adipocyte. Annu Rev Biochem 81: 715-736, 2012.

22. Farmer SR: Transcriptional control of adipocyte formation. Cell Metab 4: 263-273, 2006.

23. Nielsen R, Pedersen TA, Hagenbeek D, Moulos P, Siersbaek R, Megens E, Denissov S, Børgesen M, Francoijs KJ, Mandrup S and Stunnenberg HG: Genome-wide profiling of PPARgamma:RXR and RNA polymerase II occupancy reveals temporal activation of distinct metabolic pathways and changes in RXR dimer composition during adipogenesis. Genes Dev 22: 2953-2967, 2008.

24. Lefterova MI, Zhang Y, Steger DJ, Schupp M, Schug J, Cristancho A, Feng D, Zhuo D, Stoeckert CJ Jr, Liu XS and Lazar MA: PPARgamma and C/EBP factors orchestrate adipocyte biology via adjacent binding on a genome-wide scale. Genes Dev 22: 2941-2952, 2008.

25. Rosen ED, Walkey CJ, Puigserver P and Spiegelman BM: Transcriptional regulation of adipogenesis. Genes Dev 14: 1293-1307, 2000.

26. Kaestner KH, Christy RJ, McLenithan JC, Braiterman LT, Cornelius P, Pekala PH and Lane MD: Sequence, tissue distribution, and differential expression of mRNA for a putative insulin-responsive glucose transporter in mouse 3T3-L1 adipocytes. Proc Natl Acad Sci USA 86: 3150-3154, 1989.

27. Hwang CS, Mandrup S, MacDougald OA, Geiman DE and Lane MD: Transcriptional activation of the mouse obese (ob) gene by CCAAT/enhancer binding protein alpha. Proc Natl Acad Sci USA 93: 873-877, 1996.

28. Hwang CS, Loftus TM, Mandrup S and Lane MD: Adipocyte differentiation and leptin expression. Annu Rev Cell Dev Biol 13: 231-259, 1997.

29. Soukas A, Socci ND, Saatkamp BD, Novelli S and Friedman JM: Distinct transcriptional profiles of adipogenesis in vivo and in vitro. J Biol Chem 276: 34167-34174, 2001.

30. Kim KH, Lee K, Moon YS and Sul HS: A cysteine-rich adipose tissue-specific secretory factor inhibits adipocyte differentiation. J Biol Chem 276: 11252-11256, 2001.

31. Chang E and Kim CY: Natural products and obesity: A focus on the regulation of mitotic clonal expansion during adipogenesis. Molecules 24: 1157, 2019.

32. Park A, Kim WK and Bae KH: Distinction of white, beige and brown adipocytes derived from mesenchymal stem cells. World J Stem Cells 6: 33-42, 2014

33. Lapeire L, Hendrix A, Lambein K, Van Bockstal M, Braems G, Van Den Broecke R, Limame R, Mestdagh P, Vandesompele J, Vanhove $\mathrm{C}$, et al: Cancer-associated adipose tissue promotes breast cancer progression by paracrine oncostatin $\mathrm{M}$ and Jak/STAT3 signaling. Cancer Res 74: 6806-6819, 2014.

34. Nieman KM, Kenny HA, Penicka CV, Ladanyi A, BuellGutbrod R, Zillhardt MR, Romero IL, Carey MS, Mills GB, Hotamisligil GS, et al: Adipocytes promote ovarian cancer metastasis and provide energy for rapid tumor growth. Nat Med 17: 1498-1503, 2011.

35. Wu Q, Li J, Li Z, Sun S, Zhu S, Wang L, Wu J, Yuan J, Zhang Y, Sun $S$ and Wang C: Exosomes from the tumour-adipocyte interplay stimulate beige/brown differentiation and reprogram metabolism in stromal adipocytes to promote tumour progression. J Exp Clin Cancer Res 38: 223, 2019.

36. Balaban S, Shearer RF, Lee LS, van Geldermalsen M, Schreuder M, Shtein HC, Cairns R, Thomas KC, Fazakerley DJ, Grewal T, et al: Adipocyte lipolysis links obesity to breast cancer growth: Adipocyte-derived fatty acids drive breast cancer cell proliferation and migration. Cancer Metab 5: 1, 2017.

37. Notarnicola M, Miccolis A, Tutino V, Lorusso D and Caruso MG: Low levels of lipogenic enzymes in peritumoral adipose tissue of colorectal cancer patients. Lipids 47: 59-63, 2012.

38. Choi J, Cha YJ and Koo JS: Adipocyte biology in breast cancer: From silent bystander to active facilitator. Prog Lipid Res 69: 11-20, 2018. 
39. Fujisaki K, Fujimoto H, Sangai T, Nagashima T, Sakakibara M Shiina N, Kuroda M, Aoyagi Y and Miyazaki M: Cancer-mediated adipose reversion promotes cancer cell migration via IL- 6 and MCP-1. Breast Cancer Res Treat 150: 255-263, 2015.

40. D'Esposito V, Liguoro D, Ambrosio MR, Collina F, Cantile M, Spinelli R, Raciti GA, Miele C, Valentino R, Campiglia P, et al: Adipose microenvironment promotes triple negative breast cancer cell invasiveness and dissemination by producing CCL5. Oncotarget 7: 24495-24509, 2016.

41. Kim EJ, Kim YK, Kim S, Kim JE, Tian YD, Doh EJ, Lee DH and Chung JH: Adipochemokines induced by ultraviolet irradiation contribute to impaired fat metabolism in subcutaneous fat cells. Br J Dermatol 178: 492-501, 2018.

42. Liu L, Wu Y, Zhang C, Zhou C, Li Y, Zeng Y, Zhang C, Li R Luo D, Wang L, et al: Cancer-associated adipocytes-derived G-CSF promotes breast cancer malignancy via Stat3 signaling. J Mol Cell Biol 12: 723-737, 2020

43. Andarawewa KL, Motrescu ER, Chenard MP, Gansmuller A, Stoll I, Tomasetto C and Rio MC: Stromelysin-3 is a potent negative regulator of adipogenesis participating to cancer cell-adipocyte interaction/crosstalk at the tumor invasive front. Cancer Res 65: 10862-10871, 2005.

44. Iyengar P, Espina V, Williams TW, Lin Y, Berry D, Jelicks LA Lee H, Temple K, Graves R, Pollard J, et al: Adipocyte-derived collagen VI affects early mammary tumor progression in vivo, demonstrating a critical interaction in the tumor/stroma microenvironment. J Clin Invest 115: 1163-1176, 2005.

45. Bochet L, Lehuédé C, Dauvillier S, Wang YY, Dirat B, Laurent V, Dray C, Guiet R, Maridonneau-Parini I, Le Gonidec S, et al: Adipocyte-derived fibroblasts promote tumor progression and contribute to the desmoplastic reaction in breast cancer. Cancer Res 73: 5657-5668, 2013.

46. Côté JA, Guénard F, Lessard J, Lapointe M, Biron S, Vohl MC and Tchernof A: Temporal changes in gene expression profile during mature adipocyte dedifferentiation. Int J Genomics 2017 5149362, 2017

47. Wei X, Li S, He J, Du H, Liu Y, Yu W, Hu H, Han L, Wang C, Li H, et al: Tumor-secreted PAI-1 promotes breast cancer metastasis via the induction of adipocyte-derived collagen remodeling. Cell Commun Signal 17: 58, 2019.

48. Master SR, Hartman JL, D'Cruz CM, Moody SE, Keiper EA Ha SI, Cox JD, Belka GK and Chodosh LA: Functional microarray analysis of mammary organogenesis reveals a developmental role in adaptive thermogenesis. Mol Endocrinol 16 $1185-1203,2002$.

49. Wang F, Gao S, Chen F, Fu Z, Yin H, Lu X, Yu J and Lu C: Mammary fat of breast cancer: Gene expression profiling and functional characterization. PLoS One 9: e109742, 2014.

50. Tsoli M, Schweiger M, Vanniasinghe AS, Painter A, Zechner R, Clarke S and Robertson G: Depletion of white adipose tissue in cancer cachexia syndrome is associated with inflammatory signaling and disrupted circadian regulation. PLoS One 9: e92966, 2014.

51. Wu Q, Sun S, Li Z, Yang Q, Li B, Zhu S, Wang L, Wu J, Yuan J, Yang C, et al: Tumour-originated exosomal miR-155 triggers cancer-associated cachexia to promote tumour progression. Mol Cancer 17: 155, 2018.

52. Guerrero J, Tobar N, Cáceres M, Espinoza L, Escobar P, Dotor J, Smith PC and Martinez J: Soluble factors derived from tumor mammary cell lines induce a stromal mammary adipose reversion in human and mice adipose cells. Possible role of TGF-beta 1 and TNF-alpha. Breast Cancer Res Treat 119: 497-508, 2010

53. Stephens JM and Pekala PH: Transcriptional repression of the C/EBP-alpha and GLUT4 genes in 3T3-L1 adipocytes by tumor necrosis factor-alpha. Regulations is coordinate and independent of protein synthesis. J Biol Chem 267: 13580-13584, 1992.

54. Kim C, Lee H, Cho YM, Kwon OJ, Kim W and Lee EK: TNFalpha-induced miR-130 resulted in adipocyte dysfunction during obesity-related inflammation. FEBS Lett 587: 3853-3858, 2013.

55. Lien CC, Au LC, Tsai YL, Ho LT and Juan CC: Short-term regulation of tumor necrosis factor-alpha-induced lipolysis in 3T3-L1 adipocytes is mediated through the inducible nitric oxide synthase/nitric oxide-dependent pathway. Endocrinology 150 4892-4900, 2009.

56. Ryden M, Dicker A, van Harmelen V, Hauner H, Brunnberg M, Perbeck L, Lonnqvist F and Arner P: Mapping of early signaling events in tumor necrosis factor-alpha -mediated lipolysis in human fat cells. J Biol Chem 277: 1085-1091, 2002.
57. Zhang HH, Halbleib M, Ahmad F, Manganiello VC and Greenberg AS: Tumor necrosis factor-alpha stimulates lipolysis in differentiated human adipocytes through activation of extracellular signal-related kinase and elevation of intracellular cAMP. Diabetes 51: 2929-2935, 2002.

58. Rydén M, Arvidsson E, Blomqvist L, Perbeck L, Dicker A and Arner P: Targets for TNF-alpha-induced lipolysis in human adipocytes. Biochem Biophys Res Commun 318: 168-175, 2004.

59. Souza SC, de Vargas LM, Yamamoto MT, Lien P, Franciosa MD, Moss LG and Greenberg AS: Overexpression of perilipin A and B blocks the ability of tumor necrosis factor alpha to increase lipolysis in 3T3-L1 adipocytes. J Biol Chem 273: 24665-24669, 1998.

60. Tsoli M and Robertson G: Cancer cachexia: Malignant inflammation, tumorkines, and metabolic mayhem. Trends Endocrinol Metab 24: 174-183, 2013.

61. Arner P and Langin D: Lipolysis in lipid turnover, cancer cachexia, and obesity-induced insulin resistance. Trends Endocrinol Metab 25: 255-262, 2014.

62. Petersen EW, Carey AL, Sacchetti M, Steinberg GR, Macaulay SL, Febbraio MA and Pedersen BK: Acute IL- 6 treatment increases fatty acid turnover in elderly humans in vivo and in tissue culture in vitro. Am J Physiol Endocrinol Metab 288: E155-E162, 2005.

63. Ahmadian M, Abbott MJ, Tang T, Hudak CS, Kim Y, Bruss M, Hellerstein MK, Lee HY, Samuel VT, Shulman GI, et al: Desnutrin/ATGL is regulated by AMPK and is required for a brown adipose phenotype. Cell Metab 13: 739-748, 2011.

64. Wang YY, Attané C, Milhas D, Dirat B, Dauvillier S, Guerard A, Gilhodes J, Lazar I, Alet N, Laurent V, et al: Mammary adipocytes stimulate breast cancer invasion through metabolic remodeling of tumor cells. JCI Insight 2: e87489, 2017.

65. Ueki K, Kondo T and Kahn CR: Suppressor of cytokine signaling 1 (SOCS-1) and SOCS-3 cause insulin resistance through inhibition of tyrosine phosphorylation of insulin receptor substrate proteins by discrete mechanisms. Mol Cell Biol 24: 5434-5446, 2004.

66. Seale P, Conroe HM, Estall J, Kajimura S, Frontini A, Ishibashi J, Cohen P, Cinti S and Spiegelman BM: Prdm16 determines the thermogenic program of subcutaneous white adipose tissue in mice. J Clin Invest 121: 96-105, 2011.

67. Cannon B and Nedergaard J: Brown adipose tissue: Function and physiological significance. Physiol Rev 84: 277-359, 2004.

68. Lee J, Hong BS, Ryu HS, Lee HB, Lee M, Park IA, Kim J, Han W, Noh DY and Moon HG: Transition into inflammatory cancer-associated adipocytes in breast cancer microenvironment requires microRNA regulatory mechanism. PLoS One 12: e0174126, 2017.

69. Arora GK, Gupta A, Narayanan S, Guo T, Iyengar P and Infante RE: Cachexia-associated adipose loss induced by tumor-secreted leukemia inhibitory factor is counterbalanced by decreased leptin. JCI Insight 3: e121221, 2018.

70. Zoico E, Darra E, Rizzatti V, Budui S, Franceschetti G, Mazzali G, Rossi AP, Fantin F, Menegazzi M, et al: Adipocytes WNT5a mediated dedifferentiation: a possible target in pancreatic cancer microenvironment. Oncotarget 7: 20223-20235, 2016.

71. Kang MI, Baker AR, Dextras CR, Cabarcas SM, Young MR and Colburn NH (2012). Targeting of Noncanonical Wnt5a Signaling by AP-1 Blocker Dominant-Negative Jun When It Inhibits Skin Carcinogenesis. Genes cancer 3: 37-50, 2012.

72. Gustafson B and Smith U: Activation of canonical wingless-type MMTV integration site family (Wnt) signaling in mature adipocytes increases beta-catenin levels and leads to cell dedifferentiation and insulin resistance. J Biol Chem 285: 14031-14041, 2010.

73. Christodoulides C, Lagathu C, Sethi JK and Vidal-Puig A: Adipogenesis and WNT signalling. Trends Endocrinol Metab 20: 16-24, 2009.

74. Zoico E, Darra E, Rizzatti V, Budui S, Franceschetti G, Mazzali G, Rossi AP, Fantin F, Menegazzi M, Cinti S and Zamboni M: Adipocytes WNT5a mediated dedifferentiation: A possible target in pancreatic cancer microenvironment. Oncotarget 7: 20223-20235, 2016.

75. Bilkovski R, Schulte DM, Oberhauser F, Mauer J, Hampel B, Gutschow C, Krone W and Laudes M: Adipose tissue macrophages inhibit adipogenesis of mesenchymal precursor cells via wnt-5a in humans. Int J Obes (Lond) 35: 1450-1454, 2011.

76. Klaus A and Birchmeier W: Wnt signalling and its impact on development and cancer. Nat Rev Cancer 8: 387-398, 2008.

77. Bauer M, Bénard J, Gaasterland T, Willert K and Cappellen D: WNT5A encodes two isoforms with distinct functions in cancers. PLoS One 8: e80526, 2013. 
78. Zhuang Y, Li X, Zhan P, Pi G and Wen G: MMP11 promotes the proliferation and progression of breast cancer through stabilizing Smad2 protein. Oncol Rep 45: 16, 2021.

79. Rio MC: From a unique cell to metastasis is a long way to go: Clues to stromelysin-3 participation. Biochimie 87: 299-306, 2005.

80. Xu G, Zhang B, Ye J, Cao S, Shi J, Zhao Y, Wang Y, Sang J, Yao Y, Guan W, et al: Exosomal miRNA-139 in cancer-associated fibroblasts inhibits gastric cancer progression by repressing MMP11 expression. Int J Biol Sci 15: 2320-2329, 2019.

81. Motrescu ER, Blaise S, Etique N, Messaddeq N, Chenard MP, Stoll I, Tomasetto C and Rio MC: Matrix metalloproteinase-11/stromelysin-3 exhibits collagenolytic function against collagen VI under normal and malignant conditions. Oncogene 27: 6347-6355, 2008

82. Kozlova N, Jensen JK, Chi TF, Samoylenko A and Kietzmann T: PAI-1 modulates cell migration in a LRP1-dependent manner via $\beta$-catenin and ERK1/2. Thromb Haemost 113: 988-998, 2015.

83. Benesch MG, Ko YM, McMullen TP and Brindley DN: Autotaxin in the crosshairs: Taking aim at cancer and other inflammatory conditions. FEBS Lett 588: 2712-2727, 2014.

84. Brindley DN, Lin FT and Tigyi GJ: Role of the autotaxinlysophosphatidate axis in cancer resistance to chemotherapy and radiotherapy. Biochim Biophys Acta 1831: 74-85, 2013.

85. Choi JW and Chun J: Lysophospholipids and their receptors in the central nervous system. Biochim Biophys Acta 1831: 20-32, 2013.

86. Samadi N, Bekele R, Capatos D, Venkatraman G Sariahmetoglu M and Brindley DN: Regulation of lysophosphatidate signaling by autotaxin and lipid phosphate phosphatases with respect to tumor progression, angiogenesis, metastasis and chemo-resistance. Biochimie 93: 61-70, 2011.

87. So J, Wang FQ, Navari J, Schreher J and Fishman DA LPA-induced epithelial ovarian cancer (EOC) in vitro invasion and migration are mediated by VEGF receptor-2 (VEGF-R2). Gynecol Oncol 97: 870-878, 2005

88. Murph MM, Hurst-Kennedy J, Newton V, Brindley DN and Radhakrishna H: Lysophosphatidic acid decreases the nuclear localization and cellular abundance of the p53 tumor suppressor in A549 lung carcinoma cells. Mol Cancer Res 5: 1201-1211, 2007.

89. Popnikolov NK, Dalwadi BH, Thomas JD, Johannes GJ and Imagawa WT: Association of autotaxin and lysophosphatidic acid receptor 3 with aggressiveness of human breast carcinoma Tumour Biol 33: 2237-2243, 2012.

90. Brindley DN, Tang X, Meng G and Benesch MGK: Role of adipose tissue-derived autotaxin, lysophosphatidate signaling, and inflammation in the progression and treatment of breast cancer. Int J Mol Sci 21: 5938, 2020

91. Benesch MG, Tang X, Maeda T, Ohhata A, Zhao YY, Kok BP, Dewald J, Hitt M, Curtis JM, McMullen TP and Brindley DN: Inhibition of autotaxin delays breast tumor growth and lung metastasis in mice. FASEB J 28: 2655-2666, 2014

92. Benesch MG, Zhao YY, Curtis JM, McMullen TP and Brindley DN: Regulation of autotaxin expression and secretion by lysophosphatidate and sphingosine 1-phosphate. J Lipid Res 56: 1134-1144, 2015.

93. Benesch MG, Tang X, Dewald J, Dong WF, Mackey JR, Hemmings DG, McMullen TP and Brindley DN: Tumor-induced inflammation in mammary adipose tissue stimulates a vicious cycle of autotaxin expression and breast cancer progression. FASEB J 29: 3990-4000, 2015.

94. Russell ST, Zimmerman TP, Domin BA and Tisdale MJ: Induction of lipolysis in vitro and loss of body fat in vivo by zinc-alpha2-glycoprotein. Biochim Biophys Acta 1636: 59-68, 2004

95. Bing C, Bao Y, Jenkins J, Sanders P, Manieri M, Cinti S, Tisdale MJ and Trayhurn P: Zinc-alpha2-glycoprotein, a lipid mobilizing factor, is expressed in adipocytes and is up-regulated in mice with cancer cachexia. Proc Natl Acad Sci USA 101: 2500-2505, 2004.

96. Delort L, Perrier S, Dubois V, Billard H, Mracek T, Bing C, Vasson MP and Caldefie-Chézet F: Zinc- $\alpha 2$-glycoprotein: A proliferative factor for breast cancer? In vitro study and molecular mechanisms. Oncol Rep 29: 2025-2029, 2013.

97. Zhu H, Liu M, Zhang N, Pan H, Lin G, Li N, Wang L, Yang H, Yan $\mathrm{K}$ and Gong F: Circulating and adipose tissue mRNA levels of Zinc- $\alpha 2$-glycoprotein, leptin, high-molecular-weight adiponectin, and tumor necrosis factor-alpha in colorectal cancer patients with or without obesity. Front Endocrinol (Lausanne) 9: 190, 2018.
98. Henshall SM, Horvath LG, Quinn DI, Eggleton SA, Grygiel JJ, Stricker PD, Biankin AV, Kench JG and Sutherland RL: Zinc-alpha2-glycoprotein expression as a predictor of metastatic prostate cancer following radical prostatectomy. J Natl Cancer Inst 98: 1420-1424, 2006

99. Elattar S, Dimri M and Satyanarayana A: The tumor secretory factor ZAG promotes white adipose tissue browning and energy wasting. FASEB J 32: 4727-4743, 2018.

100. Gong FY, Zhang SJ, Deng JY, Zhu HJ, Pan H, Li NS and Shi YF: Zinc-alpha2-glycoprotein is involved in regulation of body weight through inhibition of lipogenic enzymes in adipose tissue. Int J Obes (Lond) 33: 1023-1030, 2009

101. Xiao XH, Qi XY, Wang YD, Ran L, Yang J, Zhang HL, Xu CX, Wen GB and Liu JH: Zinc alpha2 glycoprotein promotes browning in adipocytes. Biochem Biophys Res Commun 496: 287-293, 2018

102. Vlassov AV, Magdaleno S, Setterquist R and Conrad R: Exosomes: Current knowledge of their composition, biological functions, and diagnostic and therapeutic potentials. Biochim Biophys Acta 1820: 940-948, 2012.

103. Minciacchi VR, Freeman MR and Di Vizio D: Extracellular vesicles in cancer: Exosomes, microvesicles and the emerging role of large oncosomes. Semin Cell Dev Biol 40: 41-51, 2015.

104. Wang H, Liu L, Lin JZ, Aprahamian TR and Farmer SR: Browning of white adipose tissue with roscovitine induces a distinct population of UCP1(+) adipocytes. Cell Metab 24 $835-847,2016$

105. Tomasetti M, Nocchi L, Staffolani S, Manzella N, Amati M, Goodwin J, Kluckova K, Nguyen M, Strafella E, Bajzikova M, et al: MicroRNA-126 suppresses mesothelioma malignancy by targeting IRS1 and interfering with the mitochondrial function. Antioxid Redox Signal 21: 2109-2125, 2014.

106. Fong MY, Zhou W, Liu L, Alontaga AY, Chandra M, Ashby J, Chow A, O'Connor ST, Li S, Chin AR, et al: Breastcancer-secreted miR-122 reprograms glucose metabolism in premetastatic niche to promote metastasis. Nat Cell Biol 17: 183-194, 2015

107. Yan W, Wu X, Zhou W, Fong MY, Cao M, Liu J, Liu X, Chen CH Fadare O, Pizzo DP, et al: Cancer-cell-secreted exosomal miR-105 promotes tumour growth through the MYC-dependent metabolic reprogramming of stromal cells. Nat Cell Biol 20: 597-609, 2018

108. Wang S, Xu M, Li X, Su X, Xiao X, Keating A and Zhao RC: Exosomes released by hepatocarcinoma cells endow adipocytes with tumor-promoting properties. J Hematol Oncol 11: 82, 2018

109. SagarG,SahRP,JaveedN,DuttaSK,SmyrkTC,LauJS,GiorgadzeN, Tchkonia T, Kirkland JL, Chari ST and Mukhopadhyay D: Pathogenesis of pancreatic cancer exosome-induced lipolysis in adipose tissue. Gut 65: 1165-1174, 2016

110. Kong F, Li L, Du Y, Zhu H, Li Z and Kong X: Exosomal adrenomedullin derived from cancer-associated fibroblasts promotes lipolysis in adipose tissue. Gut 67: 2226-2227, 2018.

111. Hu W, Ru Z, Zhou Y, Xiao W, Sun R, Zhang S, Gao Y, Li X, Zhang $X$ and Yang H: Lung cancer-derived extracellular vesicles induced myotube atrophy and adipocyte lipolysis via the extracellular IL-6-mediated STAT3 pathway. Biochim Biophys Acta Mol Cell Biol Lipids 1864: 1091-1102, 2019.

112. Zhang H, Zhu L, Bai M, Liu Y, Zhan Y, Deng T, Yang H, Sun W, Wang X, Zhu K, et al: Exosomal circRNA derived from gastric tumor promotes white adipose browning by targeting the miR-133/PRDM16 pathway. Int J Cancer 144: 2501-2515, 2019.

113. Bhome R, Goh RW, Bullock MD, Pillar N, Thirdborough SM, Mellone M, Mirnezami R, Galea D, Veselkov K, Gu Q, et al: Exosomal microRNAs derived from colorectal cancer-associated fibroblasts: Role in driving cancer progression. Aging (Albany NY) 9: 2666-2694, 2017.

114. Au Yeung CL, Co NN, Tsuruga T, Yeung TL, Kwan SY, Leung CS, Li Y, Lu ES, Kwan K, Wong KK, et al: Exosomal transfer of stroma-derived miR 21 confers paclitaxel resistance in ovarian cancer cells through targeting APAF1. Nat Commun 7: 11150, 2016

115. Zheng Z, Liu L, Zhan Y, Yu S and Kang T: Adipose-derived stem cell-derived microvesicle-released miR-210 promoted proliferation, migration and invasion of endothelial cells by regulating RUNX3. Cell Cycle 17: 1026-1033, 2018.

116. Lazar I, Clement E, Dauvillier S, Milhas D, Ducoux-Petit M, LeGonidec S, Moro C, Soldan V, Dalle S, Balor S, et al: Adipocyte exosomes promote melanoma aggressiveness through fatty acid oxidation: A novel mechanism linking obesity and cancer. Cancer Res 76: 4051-4057, 2016. 
117. Wang J, Wu Y, Guo J, Fei X, Yu L and Ma S: Adipocyte-derived exosomes promote lung cancer metastasis by increasing MMP9 activity via transferring MMP3 to lung cancer cells. Oncotarget 8: 81880-81891, 2017.

118. Zaidi N, Lupien L, Kuemmerle NB, Kinlaw WB, Swinnen JV and Smans K: Lipogenesis and lipolysis: The pathways exploited by the cancer cells to acquire fatty acids. Prog Lipid Res 52: 585-589, 2013.

119. Kedia-Mehta N and Finlay DK: Competition for nutrients and its role in controlling immune responses. Nat Commun 10: 2123 , 2019.

120. Gonzalez-Perez RR, Xu Y, Guo S, Watters A, Zhou W and Leibovich SJ: Leptin upregulates VEGF in breast cancer via canonic and non-canonical signalling pathways and NFkappaB/HIF-1alpha activation. Cell Signal 22: 1350-1362, 2010.

121. Liu S, Lee JS, Jie C, Park MH, Iwakura Y, Patel Y, Soni M, Reisman D and Chen H: HER2 overexpression triggers an IL1a proinflammatory circuit to drive tumorigenesis and promote chemotherapy resistance. Cancer Res 78: 2040-2051, 2018.

122. Zhao J, Liu J, Wu N, Zhang H, Zhang S, Li L and Wang M: ANGPTL4 overexpression is associated with progression and poor prognosis in breast cancer. Oncol Lett 20: 2499-2505, 2020.

123. Meng L, Zhou J, Sasano H, Suzuki T, Zeitoun KM and Bulun SE: Tumor necrosis factor alpha and interleukin 11 secreted by malignant breast epithelial cells inhibit adipocyte differentiation by selectively down-regulating CCAAT/enhancer binding protein alpha and peroxisome proliferator-activated receptor gamma: Mechanism of desmoplastic reaction. Cancer Res 61: 2250-2255, 2001

124. Gray NE, Lam LN, Yang K, Zhou AY, Koliwad S and Wang JC: Angiopoietin-like 4 (Angpt14) protein is a physiological mediator of intracellular lipolysis in murine adipocytes. J Biol Chem 287: 8444-8456, 2012.
125. Kogo R, Shimamura T, Mimori K, Kawahara K, Imoto S, Sudo T, Tanaka F, Shibata K, Suzuki A, Komune S, et al: Long noncoding RNA HOTAIR regulates polycomb-dependent chromatin modification and is associated with poor prognosis in colorectal cancers. Cancer Res 71: 6320-6326, 2011.

126. Gupta RA, Shah N, Wang KC, Kim J, Horlings HM, Wong DJ, Tsai MC, Hung T, Argani P, Rinn JL, et al: Long non-coding RNA HOTAIR reprograms chromatin state to promote cancer metastasis. Nature 464: 1071-1076, 2010.

127. Ma X, Li Z, Li T, Zhu L, Li Z and Tian N: Long non-coding RNA HOTAIR enhances angiogenesis by induction of VEGFA expression in glioma cells and transmission to endothelial cells via glioma cell derived-extracellular vesicles. Am J Transl Res 9: 5012-5021, 2017.

128. Sanchez-Alvarez R, Martinez-Outschoorn UE, Lamb R, Hulit J, Howell A, Gandara R, Sartini M, Rubin E, Lisanti MP and Sotgia F: Mitochondrial dysfunction in breast cancer cells prevents tumor growth: Understanding chemoprevention with metformin. Cell Cycle 12: 172-182, 2013.

129. Munteanu R, Onaciu A, Moldovan C, Zimta AA, Gulei D Paradiso AV, Lazar V and Berindan-Neagoe I: Adipocyte-based cell therapy in oncology: The role of cancer-associated adipocytes and their reinterpretation as delivery platforms. Pharmaceutics 12 : 402, 2020.

(7) $(2)$ This work is licensed under a Creative Commons Attribution-NonCommercial-NoDerivatives 4.0 International (CC BY-NC-ND 4.0) License. 